\title{
The Influence of Emotional Well-Being and Spiritual Wholeness on Midlife Positive Functioning of Middle-Aged Professionals
}

\author{
Rigel Kate Y. Lamig ${ }^{1}$ and Chris Feli Joy P. Tajonera ${ }^{2}$ \\ 1,2University of Negros Occidental-Recoletos, Bacolod City, Philippines
}

\begin{tabular}{l} 
Article history: \\
Submitted: 12 February 2021 \\
Revised: 17 March 2021 \\
Accepted: 25 March 2021 \\
\hline Keywords: \\
Psychology \\
Emotional Well-Being \\
Spiritual Wholeness \\
Positive Functioning, \\
Correlational \\
Philippines
\end{tabular}

ABSTRACT. This descriptive-correlational study focused on the emotional wellbeing, spiritual wholeness, and positive functioning of middle-aged professionals. It aimed to measure the levels of emotional well-being, spiritual wholeness, and positive functioning; likewise, their difference when age, sex, civil and employment status, and job rank were considered. This research also intended to determine the relationship among the mentioned constructs. The study utilized tests on Emotional Well-being, Spiritual Wholeness, and Psychological Well-being Scale. Eighty-three participants from the university in Bacolod City were purposively chosen to answer these tests. Findings revealed that the levels of emotional well-being and spiritual wholeness of midlife adults were very high. Also, no significant differences in both constructs were found. The positive functioning of the respondents is high. However, an average positive functioning of single respondents was revealed when the civil status was considered. It was concluded that both emotional well-being and spiritual wholeness are significantly related to the positive functioning of midlife adults. The results of the study will be utilized for the creation of a wellness program, which aims to improve the employee's psychological well-being.

\subsection{Introduction}

The old cliché, which says "life begins at 40 ," can be a subjective statement. It is because every individual has their way of interpreting it. At forty as developmental age, people begin their midlife. Midlife is the least chartered territory in human development. It is a normal developmental life stage; meaning, it cannot be avoided. Midlife may be denied but not escaped (Johnston, 2017). The midlife experience provides an opening to psychological and spiritual growth that empowers a give-back to others and the community. It is primarily positive and has the specific goal of facilitating the process of becoming a "whole" person. This becomes a spiritual journey of humanistic growth, feeling connected to something greater than oneself (Reischer et al., 2020), and transcendence of becoming whole or connectedness with one's complete self (Sodhi, 2016).

Unfortunately, along with such a process comes discontentment and restlessness. In other words, the midlife age between 40 to 60 years old is a time in which adults take on new responsibilities and, therefore, often feel a need to reassess where they are and make changes while they think they still have time. It becomes an age of pivotal period in the life course in terms of balancing growth and decline, linking earlier and later periods of life, and bridging younger and older generations (Lachman et al., 2014). As the old proverb says, midlife is the late age of youth and the youth of old age. While the midlife person is facilitating his sense of empowerment, he is not exempted from taking a certain amount of suffering in his journey. It implies that to experience it is to live through or allow the loss, change, and let go of much of what one wishes to bring into this transition.

Coupled with the midlife journey is the journey towards career advancement. Many mid-lifers are raising careers while being on top of the game, filled with strife, crisis, extreme pleasure, and inevitable losses. Not knowing how to cope with this would mean the inability to realize one's mortality leading to a "midlife crisis" trap (Johnston, 2017) or that mentioned phenomenon. When trapped, an individual may not be as productive as he should be, for his sense of happiness and life satisfaction decreases, and his spiritual wholeness gets tampered with, leading to negative psychological functioning. In turn, he may not be able to function well enough at home, at work, and in the community. It is the very reason why this stage of development is considered one of the significant identity crises after adolescence. Elliot Jaques, the man who coined "midlife crisis," defines this state as a period where people come face-to-face with their limitations, restricted possibilities, and mortality (Strenger \& Ruttenberg, 2008).

One's emotional well-being comes into play during the individual's midlife experience. It will dictate him to assess all the positive and negative that he makes out of his life, he will have a cognitive evaluation of his happiness, satisfaction, positive emotions such as joy and pride and 
negative emotions such as pain and worry (Stiglitz et al., 2009 cited in Ulloa et al., 2013). Emotional well-being is the individual's assessment of his positive or negative affect and his overall satisfaction in life (Snyder \& Lopez, 2002). It involves feeling and expressing a wide range of emotions and learning how to manage those emotions instead of being controlled by them. Compton and Hoffman (2019) highlighted that during the midlife journey, subjective well-being reaches its minimum. Thus, it decreases at midlife. Women reach a minimum level of subjective well-being around their midforties and men in their late forties or early fifties (Compton \& Hoffman, 2012). As people age, they are consumed in their chase for self-growth and pursuance of their happiness. They pay much importance to happiness and sadness, not cultivating solid inner being such as full of peacefulness and wholeness (Sol \& Luna, 2019). The journey may affect one's positive functioning when he searched no meaning, captured no satisfying life events, elicited negative relations with others, assured no mastery with the environment, claimed insufficient growth, and attracted an unsuccessful sense of autonomy. Notably, the midlife journey may no longer be considered a crisis but a phenomenon.

Another thing that plays a role in how an individual accepts or resists midlife is his manner to search for true meaning in life. The true meaning is equated with his spiritual wholeness, which speaks of his perfect relationship with God, making him perfectly well and highly functioning (Sol \& Luna, 2019). Midlife is an opportunity for awakening into a deeper spirituality (Johnston, 2017). How spiritually mature an individual speaks of his tendency to fully function amidst the negativities that come with midlife. Such negativities one cannot live without, menopause or andropause for one, is a great change in the individual, affecting his total being. A person who has negative psychological functioning is less favored than someone who has healthy psychological well-being.

Although considerable empirical researches were concerned about well-being, such endeavors focused largely on the reports of feeling capable, happy, and satisfied using happiness and satisfaction scales (Compton \& Hoffman, 2012; Dodge et al., 2012; Stoewen, 2017). Somehow, they overlooked to measure, or minimal attention was given to the dimensions which contributed to happiness and satisfaction. When this variable is regarded having midlife adults as respondents, psychological wellbeing and emotional well-being are linked only with health or mental health (Nemati et al., 2017; Lachman, 2004; Arnett, 2018). The present study encompassed what constitutes essential features to well-being by measuring all dimensions of positive psychological functioning, emotional wellness, and spiritual wholeness of midlife adults. The results of the study will be utilized for the creation of a wellness program in the forms of seminars, training-workshops, personality development activities, and the like, which aims to improve the employee's psychological well-being.

\subsection{Framework of the Study}

Anchored on well-being, this study attuned its framework to Carol Ryff's Six-Factor Model of Psychological Well-being. The theory states that psychological well-being is attained by achieving a state of balance affected by both challenging and rewarding life events. In other words, a person can have cognitive and affective evaluations of his or her life. These evaluations include emotional reactions to events and cognitive judgments of satisfaction and fulfillment (Snyder \& Lopez, 2002).

Historically, Ryff (1995) spearheaded the research on the meaning and measurement of psychological well-being, its change, and stability across adult life. The factors, either experiential or attitudinal, explain variations in human wellness. The critical dimensions of psychological wellbeing are positive relations with others, personal growth, purpose in life, environmental mastery, and autonomy. These six dimensions of positive psychological functioning encompass a breadth of wellness that includes positive evaluation of one's self and one's life, a sense of continued growth and development as a person, the belief that life is purposeful and meaningful, the possession of good relationships with other people, the capacity to manage one's life and the surrounding world effectively, and a sense of self-determination (Ryff, 1995). Also, Ryff (2014) emphasized that the 6 dimensions were a product of differing conceptions and overlapping themes in articulating what it means to be self-actualized, individuated, fully functioning, or optimally developed. Moreover, the model of psychological well-being differs from others because it is not restricted to medical or biological descriptions instead it is a quest about the meaning of good life. Ryff (2014) believed that living a good life should be balanced and whole, engaged in different aspects of functioning positively, having that sense of purpose, and not merely being happy and satisfied. Her theory did not discount having positive emotions as contributors to positive functioning. The capacity to manage one's life and the tendency to evaluate oneself go well when one knows how to be autonomous in 
his behavior and regulate his emotions. Moreover, one's capacity to continuously find meaning in his life to feel at peace helps one fully live a life. Thus, being emotionally well and spiritually whole add to function positively in life.

Mental well-being is a multi-dimensional concept where many aspects like satisfaction, morale, positive affect, and social support constitute it. It requires a strong tendency for someone to have the capacity to perceive, understand, and manage emotions to be psychologically well. Psychological well-being is moved towards the measure of positive functioning (Ryff \& Keyes, 1995).

On emotional well-being, such as life satisfaction and happiness, the work of Tariga and Cutamora (2015) revealed that midlife adults are generally satisfied with the different aspects of their lives. Still, there are certain domains that they would very much like to improve. Arnett (2018) added that when sources of enjoyment, stress, and other mental health challenges coexist, wellbeing of midlife adults is generally high with no variation by gender, ethnicity, educational attainment, work status, or relationship status. According to the research of Kaczmarek (2004), partnered midlife men and women enjoy a much higher level of well-being and far better than non-partnered peers. It was found out in the study that marital status was the most predictive factor for variation in males' well-being, while educational attainment was the most powerful for women. Also, emotional empowerment was seen by Jiboku (2016) as more effective in enhancing psychological well-being or positive functioning in teachers who are in midlife.

Compton and Hoffman (2012) lobbied, on the other hand, that satisfaction in life by having a satisfying accomplishment in the past and present experiences and delight in relationships matter as people age. Their book concluded that the relationship between life phases and well-being depends on how well-being is measured (Guerra-Bustamante et al., 2019).

The four principal areas of spiritual wholeness, namely wisdom, practical, social, and mystical spheres, must be in harmony, fully integrated, and well-balanced to achieve spiritual growth. A person's thoughts, ways to relate with others, his tendency to do his obligations, and his desire to find God will help him achieve healthy well-being (Sol \& Luna, 2019). The person's growing ability to deal with life's situation and give him a higher satisfaction with life manifests the effect of a healthy spiritual disposition (Abadi et al., 2013).

According to previous studies, there is a positive correlation between spirituality and well-being (Nemati et al., 2017). Sodhi (2016) revealed that individuals use to apply, manifest, and embody spiritual resources, values, and qualities in ways that enhances their daily functioning and wellbeing. It is said that different facets or dimensions of religiosity or spirituality were found to be related to psychological wellbeing in different ways. The study made by Kennedy and Kanthamani (1995) showed a positive correlation between religious commitments and a person's sense of the meaning of life, which in turn, influences one's well-being. Filipinos are known to have strong spiritual beliefs. They believe in the existence of God and have a personal relationship with Him. They trust in God's plans and have the notion of non-distinction between spirituality and religiosity (Ocampo et al., 2013). These beliefs impact positive intrapersonal and interpersonal changes.

The study of Adeyemo and Adeleye (2008) indicated that religiosity, self-efficacy, and emotional intelligence have a significant relationship with mental well-being. One piece of literature (Palmer et al., 2002) cited in this study, however, believed that only a moderate correlation exists between emotional intelligence and psychological well-being.

\subsection{Methods}

This study made use of quantitative design, specifically correlational, utilizing the survey method. The research focused on 83 middle-aged employees of a Catholic University in Western Visayas, Philippines.

There were three instruments used in the study, two were modified, and one was standardized. The first researcher-made questionnaire is the 15-item test on emotional well-being adapted from Cloninger's Test (2004) on the Science of Well-being, with a 3-point scale ranging from very seldom to sometimes and almost always. Another was adapted and modified from Sol and Luna's Spiritual Maturity Test (2019), with 20 items using 4-point scales ranging from very low to very high levels. The tests incurred a 0.78 reliability index and were validated by experts with a 4.63 rating, making the test reliable and valid. Lastly, Psychological Well-being Scale, redeveloped by Ryf et al. (2007) at Stanford, was used to measure positive functioning. This is a standardized test with six dimensions: self-acceptance, positive relations with others, personal growth, purpose in life, environmental 
mastery, autonomy, and a 6-point Likert scale. It is proven to be valid and reliable at a 0.82 reliability index. A low score would mean low positive functioning.

The initial phase of this endeavor was the proposal of the study to the research office. Then, a letter addressed to the President of the University asking permission about the conduct of the study was made. When it was approved, the researcher sought the help of the Human Resource Management and Development Office (HRMDO) to identify the participants of the study. The total population of middle-aged employees was named, and they were invited to answer the test. As soon as the test administration was over, the test was checked; the data were encoded and run for statistics. A series of seminar-training was made for employees in response to their midlife functioning to further improve their psychological, emotional, and spiritual well-being. This study used descriptive, comparative, and correlational analysis to interpret data with respective statistical tools, namely, mean, T-Test, and Pearson Product Moment of Correlation.

Throughout the study, the researchers made sure that the data and personal information of the respondents were treated with the utmost confidentiality in the observance of research protocols and ethical considerations.

\subsection{Results and Discussion}

\section{Emotional well-being of midlife adults}

The emotional well-being of the respondents in general or as a whole is very high $(M=27.40$, $S D=3.10$ ). Considering all the variables of the study, a very high score was revealed. However, the lowest mean score belongs to the single respondents $(M=26.56, S D=2.80)$. Notably, a deviation from the mean score was seen as great among ANTP/NTP $(M=27.10, S D=3.53)$ respondents, which means their scores are not similar.

The results signify that midlife employees of the university generally assess their lives as satisfied in possessing positive and negative affect. They tend to feel or express a wide range of emotions and can manage these emotions pretty well without controlling them. In short, the midlife employees, regardless of their age, sex, civil status, employment status, and job rank, can understand the value of their emotions and use this accordingly, which makes them emotionally stable or emotionally well.

Table 1. Emotional well-being of middle-aged professionals

\begin{tabular}{lccl}
\hline Variables & Mean & SD & Interpretation \\
\hline $\begin{array}{l}\text { Age } \\
\quad \text { Younger }\end{array}$ & 27.00 & 3.06 & $\begin{array}{l}\text { Very High } \\
\text { Older }\end{array}$ \\
$\begin{array}{l}\text { Sex } \\
\text { Male }\end{array}$ & 27.73 & 3.12 & Very High \\
$\quad$ Female & 27.32 & 2.91 & Very High \\
Civil Status & 27.44 & 3.23 & \\
$\quad$ Single & 26.56 & 2.80 & Very High \\
$\quad$ Married & 27.60 & 3.15 & Very High \\
Employment Status & & & Very High \\
$\quad \begin{array}{l}\text { Part-time } \\
\quad \text { Permanent }\end{array}$ & 27.85 & 2.96 & Very High \\
Job Rank & 27.25 & 3.15 & Very High \\
$\quad \begin{array}{l}\text { ANTP/NTP } \\
\text { Faculty }\end{array}$ & & & Very High \\
As a Whole & 27.10 & 3.53 & Very High \\
\hline
\end{tabular}




\section{Spiritual wholeness of midlife adults}

When taken as a whole $(M=72.42, S D=7.47)$, the spiritual wholeness of the participants is also very high. A very high level of spiritual wholeness indicates that most participants, due to their faith and relationship with God, feel free of pain with nothing missing or broken and become spiritually healthy and well (Sol \& Luna, 2019). The highest mean score was shown in the group of older respondents $(M=73.44, S D=5.45)$.

Wink and Dillon (2002) emphasized that the development and expression of spiritual dimensions of the human person happen across the life span. It undergoes a drastic and significant increase in the period from middle to late adulthood. With a very high result from the respondents' spiritual wholeness, it can be explained they may have been spiritually whole prior to midlife, or that their state as midlife adults may have contributed more to it since they have been in the quest of making their lives more meaningful. As adults proceed to midlife, they are said to be more focused on spiritual aspirations, familial relations, and humanistic values. Jung's stages of life can explain that there is a vital connection between oneself and others which pushes one to view life at a larger scale and finding meaning. Also, Ryff's Theory on Psychological Well-Being in adult life reiterated that they concentrate on living their lives with meaning and a sense of purpose.

Table 2. Spiritual wholeness of middle-aged professionals

\begin{tabular}{lccc}
\hline Variables & Mean & SD & Interpretation \\
\hline $\begin{array}{l}\text { Age } \\
\quad \text { Younger }\end{array}$ & 71.21 & 9.25 & $\begin{array}{l}\text { Very High } \\
\text { Very High }\end{array}$ \\
$\begin{array}{l}\text { Older } \\
\text { Sex }\end{array}$ & 73.44 & 5.45 & \\
$\quad$ Male & & & Very High \\
$\quad$ Female & 71.39 & 8.39 & Very High \\
Civil Status & 73.04 & 6.88 & \\
$\quad$ Single & & & Very High \\
$\quad$ Married & 69.88 & 9.90 & Very High \\
Employment Status & 73.03 & 6.72 & \\
$\quad$ Part-time & & & Very High \\
$\quad$ Permanent & 72.70 & 9.48 & Very High \\
Job Rank & 72.33 & 6.80 & \\
$\quad$ ANTP/NTP & & & Very High \\
$\quad$ Faculty & 72.30 & 5.26 & Very High \\
AS a Whole & 72.49 & 8.52 & Very High \\
\hline
\end{tabular}

\section{Positive functioning of midlife adults}

The positive functioning of the participants as a whole $(M=174.41, S D=24.05)$ is high. A high score in positive functioning indicates that the majority of the participants feel highly healthy in their mind and actions, enduring attributes to self and the situation. It also indicates that the participants can relate well with others as well as themselves. Among the respondents, an average score on positive functioning was seen from the group of single adults $(M=166.06, S D=23.43)$. This could mean that the respondents who are single may be having difficulty dealing with situations that both comprise mastery and personal growth.

Whitbourne and Whitbourne (2010) emphasized that there are several things an adult gets to deal with midlife, especially with regards to relationships or relatedness with others more than with oneself. He further mentioned that once a negative feeling or thought comes into play, a person's positive functioning is damaged at a particular aspect in his lifetime.

Ryff (1995) can best explain the result of single respondents by emphasizing being whole, not only in becoming happy and satisfied but also in engaging to the different aspects of functioning positively. The midlife adults who are single may have evaluated their sense of wellness using only some dimensions of well-being as strong compared to the married ones who may have mastered all the dimensions. 
In addition, Himawan et al. (2018) stated that religiosity stimulates accepting community and psychological attachment, especially to single persons. Creating spiritual devotion with God may be beneficial to singles since it may take away loneliness and burden for them. Perhaps, this may be the reason that single persons may tend to feel whole in the different aspects of functioning despite having difficulty in achieving personal growth.

Table 3. Positive functioning of middle-aged professionals

\begin{tabular}{|c|c|c|c|}
\hline Variables & Mean & SD & Interpretation \\
\hline \multicolumn{4}{|l|}{ Age } \\
\hline Younger & 170.16 & 25.21 & High \\
\hline Older & 178.00 & 22.69 & High \\
\hline \multicolumn{4}{|l|}{ Sex } \\
\hline Male & 174.16 & 28.42 & High \\
\hline Female & 174.56 & 21.33 & High \\
\hline \multicolumn{4}{|l|}{ Civil Status } \\
\hline Single & 166.06 & 23.43 & Average \\
\hline Married & 176.40 & 23.94 & High \\
\hline \multicolumn{4}{|c|}{ Employment Status } \\
\hline Part-time & 172.40 & 28.84 & High \\
\hline Permanent & 175.05 & 22.55 & High \\
\hline \multicolumn{4}{|l|}{ Job Rank } \\
\hline ANTP/NTP & 171.83 & 25.03 & High \\
\hline Faculty & 175.87 & 23.59 & High \\
\hline As a Whole & 174.41 & 24.05 & High \\
\hline
\end{tabular}

\section{Difference in the level of emotional well-being}

The results of the independent samples t-test revealed that there is no significant difference found on the level of the emotional well-being of the participants when grouped according to age $(p=0.285)$, sex $(p=0.866)$, civil status $(p=0.232)$, employment status $(p=0.457)$ and job rank $(p=0.513)$. This is contrary to the work of Tariga and Cutamora (2015), stating that midlife adults are generally satisfied with the different aspects of their life. However, there are certain domains that they would very much like to improve. However, the result was consistent with the study of Compton and Hoffman (2012), saying that there is no decline in the person's well-being, specifically on the levels of happiness and life satisfaction as a person ages. Thus, this implies that age is not a factor that hinders the participants' happiness and satisfaction. Age also does not play a role in how a person understands or values his emotions.

The result was incongruent with the Kaczmarek (2004), stating that women were found to have greater happiness and life satisfaction than men. This sex difference was explained in terms of men's and women's social roles. Female gender roles specify more excellent emotional responsiveness, making them more emotionally stable than males. This indicates that regardless of sex, men and women can be happy, satisfied, and emotionally well. Perhaps their reasons vary, but they are contented with what they have, which Arnett (2018) has put emphasis when he said that there is complexity of wellbeing in midlife but midlife adults are generally happily stressed.

Furthermore, with regards to civil status, the result was contrary to the article of Kaczmarek (2004), who found out that partnered midlife men and women enjoy a much higher level of wellbeing and far better than non-partnered peers. In his or her study, it was found that marital status was the most predictive factor for variation in males' well-being, while educational attainment was the most powerful for women. It implies that midlife adults, whether they are married or not, are just happy and satisfied with the people around them.

This is also true among Filipinos. Since they tend to have positive traits and common religion and values, they have developed their own coping mechanism through their religious beliefs and 
informal support from family and friends (Straiton et al., 2017). Whatever their gender roles, civil status and educational attainment may be, they still find ways to nourish their well-being.

With regards to employment status and job rank, part-time and permanent, ANTP/NTP and faculty are able to express a wide variety of emotions, for one being happy or satisfied, and are able to manage them well.

Table 4. Difference in the emotional well-being of middle-aged professionals

\begin{tabular}{lllll}
\hline Variable & & t & df & p \\
\hline Age & & & & \\
Younger & Older & & & \\
27.00 & 27.73 & 1.076 & 81 & 0.285 \\
$(3.06)$ & $(3.12)$ & & & \\
\hline Sex & & & & \\
Male & Female & & & \\
27.32 & 27.44 & 0.169 & 81 & 0.866 \\
$(2.91)$ & $(3.23)$ & & & \\
\hline Civil Status & & & & \\
Single & Married & & & \\
26.56 & 27.60 & 1.204 & 81 & 0.232 \\
$(2.80)$ & $(3.15)$ & & & \\
\hline Employment Status & & & & \\
Part-time & Permanent & & & \\
27.85 & 27.25 & 0.748 & 81 & 0.457 \\
$(2.96)$ & $(3.15)$ & & & \\
\hline Job Rank & & & & \\
ANTP/NTP & Faculty & & & \\
27.10 & 27.57 & 0.657 & 81 & 0.513 \\
(3.53) & $(2.85)$ & & \\
\hline
\end{tabular}

Note: the difference in the means is significant when $p \leq 0.05$

\section{Difference in the Level of Spiritual Wholeness}

Based on the results, there is no significant difference in the spiritual wholeness of respondents when age $(p=0.176)$, sex $(p=0.333)$, civil status $(p=0.130)$, employment status $(p=0.850)$, and job rank $(p=0.912)$ are considered.

The results of the study strengthened the claims of Ocampo et al. (2013) that Filipinos are known to have strong spiritual beliefs that regardless of age, sex, civil status, or any variable, as long as there is that growing ability from each of them to deal with life's situation, they get fulfilled. This gives them, like in the case of the respondents, higher satisfaction with life, and this manifests a healthy spiritual disposition (Abadi et al., 2013).

The findings did not coincide with the statements of Himawan et al., (2018), which said that religiosity stimulates accepting community and psychological attachment, especially to single persons. Moreover, they emphasized that creating spiritual devotion with God may be beneficial to singles since it may take away loneliness and burden for them.

Regarding sex, Rich (2012) also mentioned that women gained a higher score than men in religiosity. In this case, spiritual attachment works on a purpose to satisfy the need of every person, single or not, to be secured and to belong. 
Table 5. Difference in the spiritual wholeness of middle-aged professionals

\begin{tabular}{lllll}
\hline Variable & & t & df & p \\
\hline Age & & & & \\
Younger & Older & & & \\
71.21 & 73.44 & 1.364 & 81 & 0.176 \\
$(9.25)$ & $(5.45)$ & & & \\
\hline Sex & & & & \\
Male & Female & & & \\
71.39 & 73.04 & 0.974 & 81 & 0.333 \\
$(8.39)$ & $(6.88)$ & & & \\
\hline
\end{tabular}

\section{Civil Status}

\begin{tabular}{lllll} 
Single & Married & & & \\
69.88 & 73.03 & 1.530 & 81 & 0.130 \\
$(9.90)$ & $(6.72)$ & & & \\
\hline
\end{tabular}

Employment Status

\begin{tabular}{lllll} 
Part-time & Permanent & & & \\
72.70 & 72.33 & 0.190 & 81 & 0.850 \\
$(9.48)$ & $(6.80)$ & & & \\
\hline
\end{tabular}

\begin{tabular}{lllll}
\hline Job Rank & & & & \\
ANTP/NTP & Faculty & & & \\
72.30 & 72.49 & 0.111 & 81 & 0.912 \\
$(5.26)$ & $(8.52)$ & & & \\
\hline
\end{tabular}

Note: the difference in the means is significant when $p \leq 0.05$

\section{Difference in the level of positive functioning}

The results revealed that there is no significant difference in positive functioning when age $(p=0.140)$, sex $(p=0.943)$, civil status $(p=0.123)$, employment status $(p=0.671)$, and job rank $(p=0.466)$ are considered.

These claims tend to strengthen the concept of Guerra-Bustamante et al. (2019) about positive functioning that when a person develops and has reached his full potential, he tends to function pleasantly psychologically. This claim is evident regardless of age, sex, civil status, employment status, or job rank.

The findings of the study did not coincide with the claims of Ryff (2014) which states welleducated women in multiple roles show higher levels of wellbeing compared with men. In this case, no difference in the level of positive functioning was shown when sex is considered. Moreover, married individuals were also said to have an advantage with regards wellbeing compared to single individuals. Maybe, Jiboku (2016) was correct after saying that empowerment matters more to function positively.

\section{Relationship between emotional well-being, spiritual wholeness, and positive functioning}

Findings further revealed a significant relationship between emotional well-being and spiritual wholeness with a P-value of 0.000 . It means that emotional well-being is related to spiritual wholeness. A person who is emotionally well is considered a spiritual whole person. It proves the claim of Adeyemo and Adeleye (2008) that a spiritual life embodied in a strong relationship with God and the community increases well-being. Furthermore, the result of the study strengthened the findings of Sodhi (2016) who found out that religiosity or spirituality is a predictor of well-being. To be spiritually healthy, one has to possess healthy well-being, and that is one with a strong relationship with the 
Supreme Being, with himself, the society, and the environment that nurtured it. Thus, a healthy spiritual disposition is an indicator of one's life satisfaction (Abadi et al., 2013).

Table 6. Difference in the positive functioning of middle-aged professionals

\begin{tabular}{|c|c|c|c|c|}
\hline Variable & & $\mathbf{t}$ & df & $\mathbf{p}$ \\
\hline \multicolumn{5}{|l|}{ Age } \\
\hline Younger & Older & & & \\
\hline 170.16 & 178.00 & 1.491 & 81 & 0.140 \\
\hline$(25.21)$ & (22.69) & & & \\
\hline \multicolumn{5}{|l|}{ Sex } \\
\hline Male & Female & & & \\
\hline 174.16 & 174.56 & 0.072 & 81 & 0.943 \\
\hline$(28.42)$ & $(21.33)$ & & & \\
\hline \multicolumn{5}{|l|}{ Civil Status } \\
\hline Single & Married & & & \\
\hline 166.06 & 176.40 & 1.559 & 81 & 0.123 \\
\hline$(23.43)$ & (23.94) & & & \\
\hline \multicolumn{5}{|c|}{ Employment Status } \\
\hline Part-time & Permanent & & & \\
\hline 172.40 & 175.05 & 0.427 & 81 & 0.671 \\
\hline$(28.84)$ & $(22.55)$ & & & \\
\hline \multicolumn{5}{|l|}{ Job Rank } \\
\hline ANTP/NTP & Faculty & & & \\
\hline 171.83 & 175.87 & 0.732 & 81 & 0.466 \\
\hline$(25.03)$ & (23.59) & & & \\
\hline
\end{tabular}

Note: the difference in the means is significant when $p \leq 0.05$

The result of the study also showed that there is a significant relationship between emotional well-being and positive functioning $(p=0.004)$. It means that the respondents' emotional well-being is related to their positive functioning. This implies that midlife adults who have the need to reassess their life and its meaning may have emotional stability and, at the same time, are directed towards positive functioning. The respondents' ability to understand the value of their emotions and the ability to carry their emotions out affect in any way how healthy their mind and actions are. Likewise, this emotional maturity influences their relatedness with oneself, with others, and with the situation.

Table 7. Relationship between emotional well-being, spiritual wholeness, and positive functioning of middle-aged professionals

\begin{tabular}{lccc}
\hline Variable & r & df & p \\
\hline Emotional Well-being x Spiritual Wholeness & $0.407^{*}$ & 81 & 0.000 \\
Emotional Well-being x Positive Functioning & $0.309^{*}$ & 81 & 0.004 \\
Spiritual Wholeness x Positive Functioning & $0.251^{*}$ & 81 & 0.022 \\
\hline
\end{tabular}

Note: *the correlation is significant when $\mathrm{p} \leq 0.05$

The findings of the present study deny the conclusion of Compton and Hoffman (2012), who lobbied that relationship between life phases, whether a happy past or a satisfying present full of pleasant or unpleasant emotions and well-being, may not always be associated because it will depend so much on how well-being is measured, in this case, the midlife adults' positive functioning. It may also mean that midlife adults who are emotionally mature are expected to function positively well in mind and actions fully. 
The findings of the study revealed that there is a significant relationship between spiritual wholeness and positive functioning $(P=0.022)$. This result signifies that the participants' spiritual health is connected with how they deal with themselves and others. This is congruent with the study of Nemati et al. (2017), which stated a positive correlation between spirituality and well-being. According to previous studies, spiritual intelligence increases one's adjustment. It covers a set of capacities, spiritual resources, and capabilities; thus, it increases mental health.

The results of the study strengthened Ryff's Theory on the Six-Factor Model of Psychological Well-being. It is said that positive psychological functioning encompasses a breadth of wellness that includes a sense of evaluation of self and others, may it be in terms of emotions, relationships, and life's purpose. A midlife adult has been influenced, based on the findings, to have that belief regarding a meaningful life and successful management of one's feelings or reactions as he walks through his journey towards positive functioning.

\subsection{Conclusion}

Both emotional well-being and spiritual wholeness are significantly related to the positive functioning of the participants. Therefore, with the results presented, it is determined that with high emotional well-being and spiritual wholeness, a person can function positively. The person is likely to deal with life's hassles and struggles during midlife in a healthy manner, describing and understanding thoroughly his emotions and others' emotions. He also tends to be equipped to strengthen his relationship with the Divine and define his sense of purpose in life. In other words, the higher an individual's emotional well-being and spiritual wholeness, the higher he seems to relate with others and self-refer to mastery and personal growth. It could have been better if the six dimensions of positive functioning or psychological well-being were treated and presented separately to distinguish which dimension is the weakest area and later be improved. Nonetheless, the overall results yielded a favorable outcome to the respondents in terms of dealing with life, managing their emotions, evaluating their spirituality, and functioning positively.

\section{REFERENCES}

Abadi, M., Mozaffari, M., Tabbodi, M., \& Rahgozar, H. (2013). The relationship between spiritual wellbeing and academic achievement. European Online Journal of Natural and Social Sciences Proceedings Vol. 2I No. 3(5) (2013). www.european-science.com.

Adeyemo, D. A. \& Adeleye, A. T. (2008). Emotional intelligence, religiosity and self-efficacy as predictors of psychological wellbeing among secondary school adolescents in Ogbomoso, Nigeria. Europe's Journal of Psychology Vol. 4 No. 1 (2008).

Arnett, J. (2018). Happily stressed: The complexity of wellbeing in midlife. Journal of Adult Development 25 270-278. https://doi.org/10.1007/510804-018-9291-3.

Cloninger, C. R. (2004). Feeling good: the science of well-being. Oxford University Press.

Compton, W. C., \& Hoffman, E. (2019). Positive psychology: The science of happiness and flourishing. Sage Publications.

Compton, W. \& Hoffman, E. (2012). Positive psychology: A workbook for personal growth and wellbeing. Wadsworth Cengae Learning, USA.

Dodge, R., Daly, A., Huyton, J., \& Sanders, L. (2012). The challenge of defining wellbeing. International Journal of Wellbeing 2(3), 222-235. https://doi:10.5502/ijw.v2i3.4Rachel

Guerra- Bustamante, J., Leon-del-Barco, B., Yuste-Tosina, R., Lopez-Ramos, V. M., \& Mendo-Lazaro, S. (2019). Emotional intelligence and psychological wellbeing in adolescents. International Journal of Environmental Research and Public Health, 2019, 16, 2-12.

Himawan, K. K., Bambling, M., \& Edirippulige, S. (2018). Singleness, religiosity, and the implications for counselors: The Indonesian case. Europe's journal of psychology, 14(2), 485.

Jiboku, A. O. (2016). Effects of emotional empowerment and self-efficacy techniques on the psychological well-being of secondary school teachers in Ogun State, Nigeria: An empirical analysis. SMCC Higher Education Research Journal, 2(1). http://ejournals.ph/ form/cite. php?id=9764.

Johnston, J. C. (2017). Midlife maze: A map to recovery and rediscovery after loss. Rowman \& Littlefield.

Kaczmarek, M. (2004). The midlife well-being, gender and marital status. Anthropological Review, 67, 57-71. 
Kennedy, J. E. \& Kanthamani, H. (1995). Empirical support for model of wellbeing, meaning in life, importance of religion and transcendent experiences. http://jeksite.org/research/path.pdf.

Lachman, M. E. (2004). Development in midlife. Annu. Rev. Psychol., 55, 305-331.

Lachman, M., Teshale, S., \& Agrigoroaei, S. (2014). Midlife as a pivotal period in the life course: balancing growth and decline at the crossroads of youth and old age. International Journal of Behavioral Development Vol. 39 issue 1 (2015). https://doi.or/10.1177/0165025414533223.

Nemati, E., Habibi, M., Ahmadian Vargahan, F., Soltan Mohamadloo, S., \& Ghanbari, S. (2017). The role of mindfulness and spiritual intelligence in students' mental health. Journal of Research and Health, 7(1), 594-602. https://doi.org/10.18869/acadpub.jrh.7.15.94.

Ocampo, A., Mansukhani, R., Mangrobang, B. \& Juan, A. (2013). Influences and perceived impact of spirituality on Filipino adolescents. Philippine Journal of Psychology, 46(1). http://ejournals.ph/ form/ cite.php?id=3865.

Palmer, B., Donaldson, C., \& Stough, C. (2002). Emotional intelligence and life satisfaction. Personality and Individual Differences Vol. 33, Issue 7, Nov. 2002, 1091-1100. https://doi. org/10.1016/ 50191-8869(01)00215-X.

Reischer, H., Roth, L., Villarreal, J., \& McAdams, D. (2020). Self-transcendence and life stories of humanistic growth among late-midlife adults. Journal of Personality. https://doi.org/10.1111/ jopy.12583

Rich, A. (2012). Gender and spirituality are women really more spiritual? Liberty University Spring. https://pdfs.semanticscholar.org/4630/ e0dfdcf154c07dd3756bcceca9ff5eb5a46f.pdf.

Ryff, C. D. (2014). Psychological wellbeing revisited: Advances in the science and practice of eudaimonia. Psychotherapy and Pscyhosomatic. https://doi.or/10.1159/000353263.

Ryff, C. D. (1995). Psychological wellbeing in adult life. Current Directions in Psychological Science. https://doi.org/10.1111/1467-821.ep10772395.

Ryff, C. D. \& Keyes, C. L. M. (1995). The structure of psychological wellbeing revisited. Journal of Personality and Social Psychology, 69(4), 719-727. https://doi.org/10.1037/0022-3514.69.4.719.

Straiton, M. L., Ledesma, H. M. L., \& Donnelly, T. T. (2017). A qualitative study of Filipina immigrants' stress, distress and coping: the impact of their multiple, transnational roles as women. BMC Women's Health, 17(1), 72. doi: 10.1186/s12905-017-0429-4.

Strenger, C. \& Ruttenberg, A. (2008). The existential necessity of midlife change. Harvard Business Review. https://hbr.org/2008/02/the-existential-necessity-of-midlife-change.

Snyder, C. R. \& Lopez, S. (2002). Handbook of positive psychology. Oxford University Press, New York.

Sodhi, R. (2016). Emotional intelligence and spirituality: A review. International Journal of Indian Psychology Vol. 4, Issue No. 82. http://www.ijip.in.

Sol, M. \& Luna, A. (2019). The spiritual awakening process. Aletheia Luna and Mateo So. ISBN 9781370002900.

Stoewen, D. (2017). Dimensions of wellness: Change your habits, change your life. Canadian Veterinarian Journal, 58(8): 861-862. ncbi.nih.gov/pmc/articles/PMC5508938.

Tariga, J.A. \& Cutamora, J. C. (2015). Predictors of subjective wellbeing among elderly. Recoletos Multidisciplinary Research Journal, 3(2). http://ejournals.ph/ form/cite.php?id=13193.

Ulloa, B., Moller, V., \& Sousa-Poza, A. (2013). How does subjective wellbeing evolve with age: A literature review. Institute for the Study of Labor, Germany.

Wink, P. \& Dillon, M. (2002). Spiritual development across the adult life course: Findings from a longitudinal study. Journal of Adult Development 9, 79-94 (2002). https://doi.org/10.1023/A: 1013883419122.

Whitbourne, S. K., \& Whitbourne, S. B. (2010). Adult development and aging: Biopsychosocial perspectives. John Wiley \& Sons.

\section{Correspondence:}

RIGEL KATE Y. LAMIG

rgelk8@gmail.com

https://orcid.org/0000-0003-4676-8456

CHRIS FELI JOY P. TAJONERA

chrisfelijoy@gmail.com

https://orcid.org/0000-0002-4898-2950 